\title{
The application value of lung ultrasound findings in preterm infants with bronchopulmonary dysplasia
}

\author{
Shuqiang Gao ${ }^{1,2}$, Tiantian Xiao ${ }^{2}$, Rong $\mathrm{Ju}^{2}$, Rongchuan $\mathrm{Ma}^{2}$, Xiaolong Zhang ${ }^{2}$, Wenbin Dong ${ }^{1}$ \\ ${ }^{1}$ Department of Newborn Medicine, The Affiliated Hospital of Southwest Medical University, Luzhou 646000, China; ${ }^{2}$ Department of Neonatology, \\ Chengdu Women's and Children's Central Hospital, School of Medicine, University of Electronic Science and Technology of China, Chengdu \\ 611731, China \\ Contributions: (I) Conception and design: S Gao, W Dong; (II) Administrative support: T Xiao, R Ju; (III) Provision of study materials or patients: \\ S Gao, R Ju, R Ma, W Dong; (IV) Collection and assembly of data: All authors; (V) Data analysis and interpretation: X Zhang, T Xiao, R Ju; (VI) \\ Manuscript writing: All authors; (VII) Final approval of manuscript: All authors. \\ Correspondence to: Wenbin Dong. Department of Newborn Medicine, The Affiliated Hospital of Southwest Medical University, Luzhou 646000, \\ China. Email: dongwenbinw@163.com.
}

\begin{abstract}
Background: The purpose of this study was to investigate the association between ultrasound findings and preterm infants with bronchopulmonary dysplasia (BPD).

Methods: Preterm infants with a gestation age of less than 28 weeks or birthweight less than 1,500 $\mathrm{g}$ admitted to the neonatal intensive care unit (NICU) in the Chengdu Women's \& Children's Central Hospital from June 2018 to June 2019 were enrolled in the study and divided into 2 groups: the BPD group and the non-BPD group. All clinical data and lung ultrasound were retrospectively analyzed.

Results: A total of 81 neonates (gestational age $=29.71 \pm 2.27$ weeks; birth weight $=1,189.5 \pm 184.5 \mathrm{~g}$ ) were enrolled in our center. The regression analysis showed that gestational age [odds ratio $(\mathrm{OR})=0.57 ; 95 \%$ confidence interval (CI): 0.42-0.77, $\mathrm{P}=0.0002$ ], birthweight $(\mathrm{OR}=0.99 ; 95 \% \mathrm{CI}$ : 0.99-1.00, $\mathrm{P}<0.0001)$, mild asphyxia (OR =3.3; 95\% CI: 1.24-8.74, $\mathrm{P}=0.0165)$, anemia (OR =4.43; 95\% CI: 1.34-14.64, P=0.0146), blood transfusion $(\mathrm{OR}=3.68$; 95\% CI: $1.38-9.79, \mathrm{P}=0.0090)$, respiratory failure $(\mathrm{OR}=6.58 ; 95 \% \mathrm{CI}: 1.27-34.08$, $\mathrm{P}=0.0486$ ), heart failure ( $\mathrm{OR}=6.58 ; 95 \% \mathrm{CI}: 1.27-34.08, \mathrm{P}=0.0248)$, and "debris" lung ultrasound findings $(\mathrm{OR}=21.82$; 95\% CI: 2.63-181.11, $\mathrm{P}=0.0043)$ were correlated with BPD.
\end{abstract}

Conclusions: BPD-related lung ultrasound findings can be a kind of imaging marker to diagnose BPD.

Keywords: Preterm infants; ultrasound finding; bronchopulmonary dysplasia (BPD)

Submitted Feb 17, 2020. Accepted for publication Mar 16, 2020.

doi: $10.21037 /$ tp.2020.03.14

View this article at: http://dx.doi.org/10.21037/tp.2020.03.14

\section{Introduction}

Bronchopulmonary dysplasia (BPD) is one of the most common and severe respiratory diseases in preterm infants, especially those of extreme preterm birth and very low birthweight, and was thought to be a chronic progressive lung injury, along with pulmonary parenchyma and vascular changes (1). Compared to non-BPD children, children with BPD have a significantly higher risk of pulmonary dysfunction, speech impairment, cerebral palsy, hearing and vision impairment like in retinopathy of prematurity, and long-term cognitive dysfunction $(2,3)$. BDP prevalence varies widely across different countries, ranging from $10 \%$ to $89 \%$ worldwide. A study in China showed that BPD affects up to $82 \%$ of the population of infants with a gestation age from 24 to 28 weeks (4). The main reasons of this phenomenon include the different diagnostic criteria in studies, infants involved with different gestational ages and weights, and the various diagnosis and treatment strategies applied in different centers (5). Thus, it is very important to define the incidence of BPD, and to unify the diagnostic criteria and treatment strategies for the clinical management of very premature infants and the study of new 
treatment options (3). Northway was first to describe the clinical manifestations of BPD and its typical X-ray findings in near-term infants in 1967 (6), but the lung X-ray findings are no longer used as a criterion for assessing the severity of BPD at present (7). There are many studies focusing on the clinical prediction models and biochemical predictors of BPD, but only a few studies on the changes in lung ultrasound images (8). In recent years, with the development of ultrasound diagnostic technology, the value of ultrasound in lung diseases has gradually been recognized, especially in the newborns (9). The study presented here investigated the diagnostic value of lung ultrasound findings in preterm infants with BPD.

\section{Methods}

\section{Patients}

We conducted a retrospective, single-center study of preterm infants. The data of preterm infants with a gestational age $\leq 28$ weeks or a birth weight $\leq 1,500 \mathrm{~g}$, who were admitted to the Chengdu Women's and Children's Central Hospital, between June 2018 and June 2019, were collected.

Cases were excluded from analysis if the infants had congenital malformations (such as congenital heart disease, diaphragmatic hernia, pulmonary bulla, congenital cystic adenomatoid malformation of the lung (CCAM), craniocerebral malformation, etc.) or incomplete clinical data.

\section{Methodology}

The diagnostic criteria for BPD were infants with oxygen dependence $(<0.21) 28$ days after birth and a gestational age less than 32 weeks (10). According to fraction of inspiration $\left(\mathrm{FiO}_{2}\right)$ at 36 weeks' gestational age or at discharge, we divided BPD levels as follows: (I) mild, without oxygen; (II) moderate, $\mathrm{FiO}_{2}<0.30$; (III) severe, requires $\mathrm{FiO}_{2}>0.30$ and/or continuous positive airway pressure (CPAP), or mechanical ventilation.

Lung ultrasound was taken and read by 2 well-trained ultrasound surgeons during BPD routine ultrasound screening (Table 1). The machine used for lung ultrasound was the PHILIPS CX50 portable ultrasound diagnostic instrument, with linear array probe at a frequency of 12 to $13 \mathrm{mHZ}$.
According to the lung ultrasound acquisition standard described in previous work (11), we developed the standard in our center. First, children were supine to check the anterior chest to see whether there was pneumothorax or other symptoms. Then, the scan was extended to the lateral chest to check whether there was pleural effusion or lung disease. Finally, patients lay in the lateral or prone position so the presence of pleural lesions and consolidation could be determined according to the pathogenetic condition. We distinguished pneumothorax, pleural effusion, pulmonary edema, pulmonary consolidation, atelectasis, and other disease according to the signs of pleural slip, A line, B line, lung point, bronchial inflation, and so on. Each side of the chest wall was divided into 6 sections based on the parasternal line, anterior axillary line, posterior axillary line, and extension line of double nipple, which included the anterior upper, lower anterior, lower axillary, upper axillary, posterior upper, and lower posterior sections, and recorded as L1-6 and R1-6 images, respectively. Cross-section and longitudinal-section audiograms were acquired and marked, and surface signs were labeled if necessary. We took at least 12 images in double-picture mode. Lung ultrasound was acquired once a week from 3 weeks after birth to discharge. Statistics were accumulated for abnormal changes in ultrasound findings. The specification of lung ultrasound diagnosis of BPD was listed as follows: (I) changes in pleural line such as interruption, disappearance, thinning, and thickening; (II) presence of B line which indicated fusion or alveolar interstitial syndrome (Figure 1); (III) a section of pulmonary consolidation with subpleural structure disorders, fragment-like strong echoes, and irregular weak echo areas visible below (Figure 2); (IV) pleural effusion; (V) radiographic evaluation of various complications, such as lung abscess; (VI) the presence of slippery lung syndrome.

\section{Statistical analysis}

Statistical analysis was performed using SPSS, version 19.0 (IBM Corp). The mean of normal distribution was assessed with measurement data presented as a percentage. The median (maximum and minimum) was estimated in nonnormal distribution data. Factors such as gender, gestational age, birth weight, asphyxia, and complications were assigned to variables, and univariate analysis was performed to calculate the odds ratios (OR) and their 95\% confidence intervals (CI). Logistic multiple regression analysis was performed on the multiple factors above to calculate OR 
Translational Pediatrics, Vol 9, No 2 April 2020

Table 1 Characteristics of infants in this study

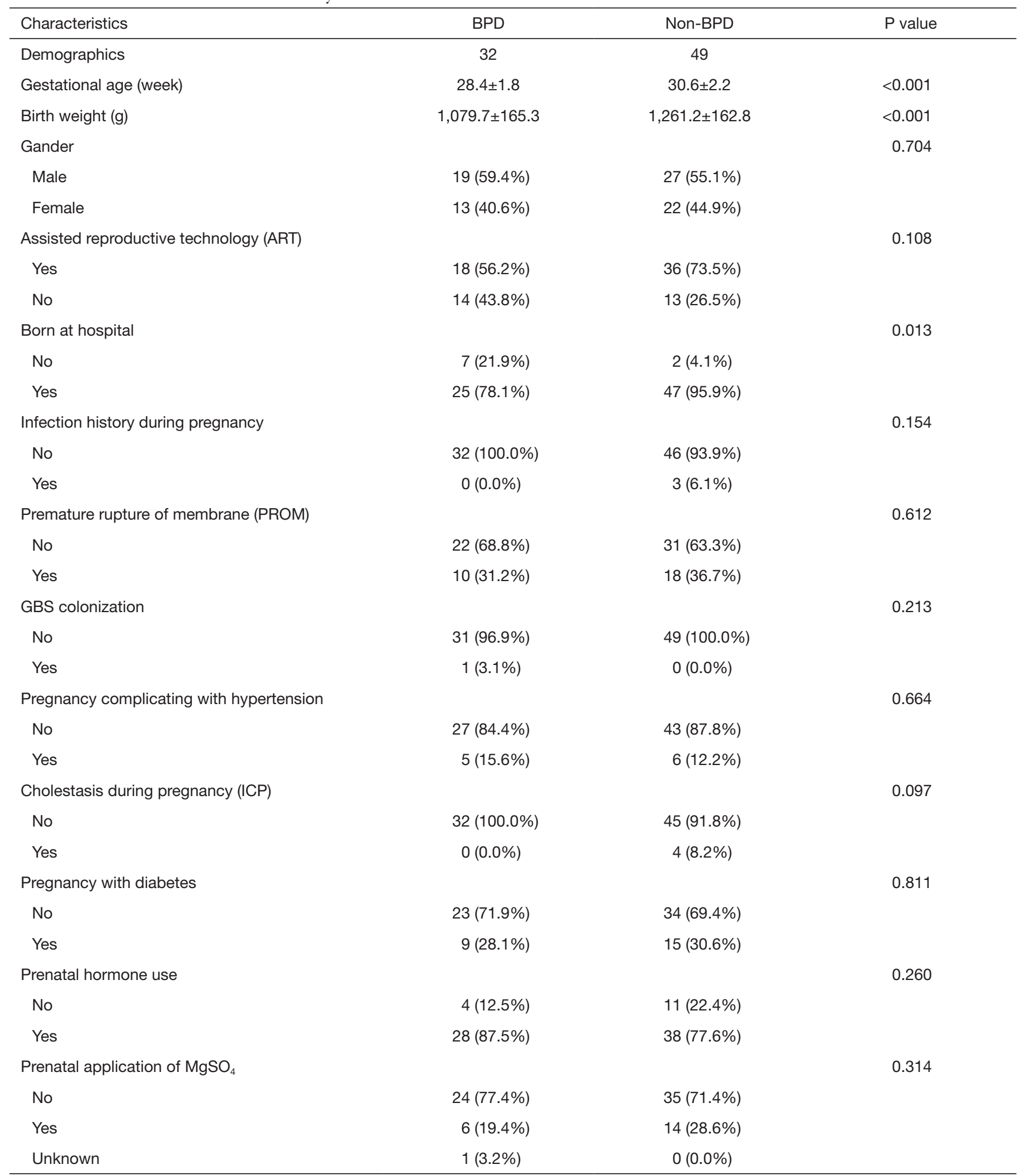

BPD, bronchopulmonary dysplasia; GBS, Streptococcus agalactiae. 

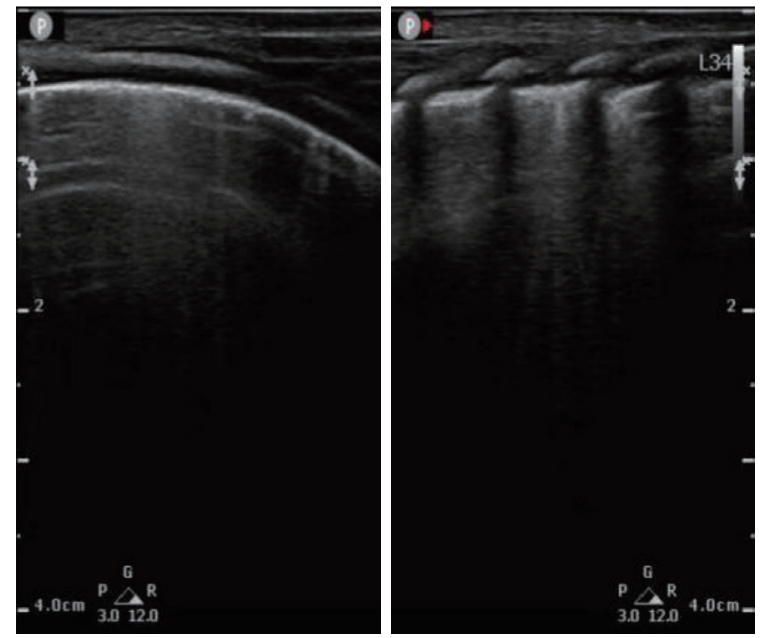

Figure 1 Lung ultrasound showed "alveolar interstitial syndrome" in BPD patients. BPD, bronchopulmonary dysplasia.
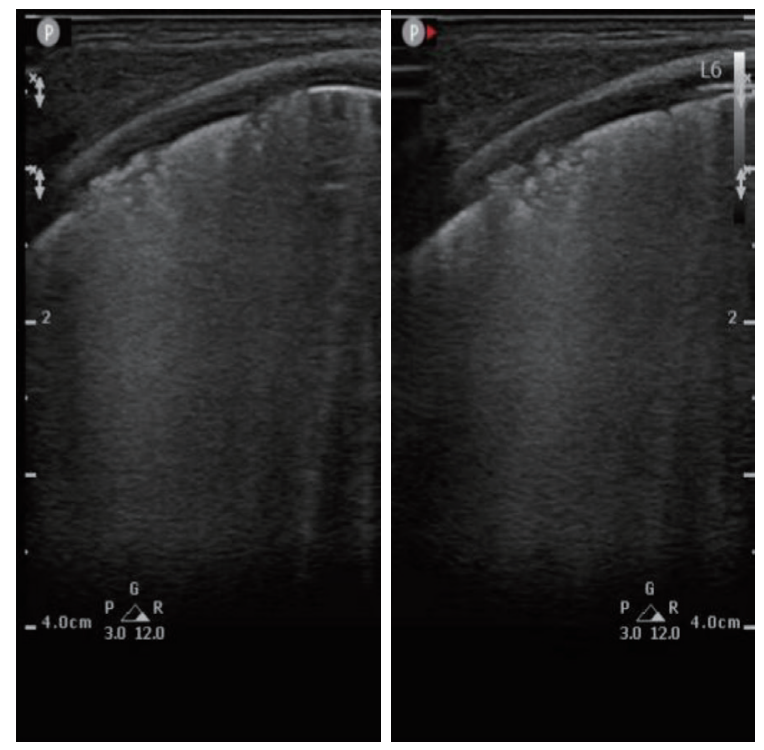

Figure 2 "Debris" lung ultrasound findings in BPD patients. BPD, bronchopulmonary dysplasia.

and its $95 \%$ CI. Results with $\mathrm{P}<0.05$ were considered statistically significant.

\section{Results}

\section{Basic situation}

In this study, the incidence of BPD was $39.5 \%$ among the enrolled 81 preterm infants (gestational age $\leq 28$ weeks or birth weight $\leq 1,500 \mathrm{~g}$ ) from June 2018 to June 2019 .
There were 46 male and 35 female infants, with an average gestational age of $29.71 \pm 2.27$ weeks and average birth weight of $1,189.5 \pm 184.5 \mathrm{~g}$. For BPD patients, the average hospitalization day was 58.8 days (Figure S1).

\section{Single factor analysis of clinical bigh-risk factors in the BPD group and non-BPD group (Table 2)}

The results indicated that the clinical risk was significantly different between the BPD group and non-BPD group children with a gestational age of $28.4 \pm 1.8$ weeks and a birth weight of $1,079.7 \pm 165.3 \mathrm{~g}$. The regression analysis showed that gestational age (OR $=0.57 ; 95 \% \mathrm{CI}: 0.42-0.77$, $\mathrm{P}=0.0002)$, body weight $(\mathrm{OR}=0.99 ; 95 \%$ CI: $0.99-1.00$, $\mathrm{P}<0.0001)$, mild asphyxia (OR $=3.3$; $95 \%$ CI: $1.24-8.74$, $\mathrm{P}=0.0165)$, anemia $(\mathrm{OR}=4.43 ; 95 \% \mathrm{CI}: 1.34-14.64$, $\mathrm{P}=0.0146)$, blood transfusion $(\mathrm{OR}=3.68$; $95 \% \mathrm{CI}: 1.38$ 9.79; $\mathrm{P}=0.0090)$, respiratory failure $(\mathrm{OR}=6.58 ; 95 \% \mathrm{CI}$ : 1.27-34.08, $\mathrm{P}=0.0486)$, and cardiac insufficiency $(\mathrm{OR}=6.58$; 95\% CI: $1.27-34.08, \mathrm{P}=0.0248$ ) were all clinical risk factors in BPD and showed significant difference compared to the non-BPD group.

\section{Multivariate analysis of clinical data in the BPD group (Table 3)}

Multivariate analysis of clinical data indicated that blood product $(\mathrm{OR}=5.49 ; 95 \% \mathrm{CI}: 0.042-0.791, \mathrm{P}=0.023)$ was independent high risk factor of BPD.

\section{Univariate analysis lung ultrasound findings in the BPD group and non-BPD group}

The ultrasound result indicated that presence of "debris" lung ultrasound findings (OR $=21.82$; 95\% CI: 2.63-181.11, $\mathrm{P}=0.0043$ ) was correlated with BPD and could be a highrisk factor for BPD (Table 4).

\section{Discussion}

Currently, the consensus BPD definition is the one proposed in 2000 by the National Institute of Child Health and Human Development (NICHD) (10) whose main diagnostic criterion was infants acknowledged to have been treated with oxygen for over 28 days and at 36 weeks' corrected age. Research indicates that assessment of oxygen dependence can be used to identify the mild, moderate, and severe categories of BDP, but is insufficient in predicting 
Table 2 Single factor analysis of clinical high-risk factors between the BPD group and non-BPD group

\begin{tabular}{|c|c|c|c|c|c|}
\hline Variable & BPD & Non-BPD & $P$ value & OR, $95 \% \mathrm{Cl}$ & $P$ value \\
\hline Gestational age (week) & $28.4 \pm 1.8$ & $30.6 \pm 2.2$ & $<0.001$ & $0.57(0.42,0.77)$ & 0.0002 \\
\hline Birth weight $(\mathrm{g})$ & $1,079.7 \pm 165.3$ & $1,261.2 \pm 162.8$ & $<0.001$ & $0.99(0.99,1.00)$ & $<0.0001$ \\
\hline Assisted reproductive technology (ART) & $13(26.5 \%)$ & $14(43.8 \%)$ & 0.108 & $2.15(0.84,5.53)$ & 0.1109 \\
\hline Pregnancy complicating with hypertension & $6(12.2 \%)$ & $5(15.6 \%)$ & 0.664 & $1.33(0.37,4.78)$ & 0.6649 \\
\hline Pregnancy with diabetes & $15(30.6 \%)$ & $9(28.1 \%)$ & 0.796 & $0.89(0.33,2.37)$ & 0.8106 \\
\hline Prenatal hormone use & $38(77.6 \%)$ & $28(87.5 \%)$ & 0.260 & $2.03(0.58,7.03)$ & 0.2659 \\
\hline Prenatal application of $\mathrm{MgSO}_{4}$ & $14(28.6 \%)$ & $6(19.4 \%)$ & 0.314 & $0.63(0.21,1.86)$ & 0.3973 \\
\hline Severe & $2(4.1 \%)$ & $4(12.5 \%)$ & & $5.82(0.93,36.29)$ & 0.0593 \\
\hline Caffeine use & $24(75 \%)$ & $23(47 \%)$ & 0.017 & $8.97(1.10,73.32)$ & 0.0406 \\
\hline Postnatal blood transfusion & $24(75 \%)$ & $21(43 \%)$ & 0.004 & $3.68(1.38,9.79)$ & 0.0090 \\
\hline Alveolar surfactant use & $26(81 \%)$ & $35(71 \%)$ & 0.316 & $1.61(0.54,4.80)$ & 0.3931 \\
\hline Azithromycin use & $6(19 \%)$ & $6(12 \%)$ & 0.420 & $1.65(0.48,5.67)$ & 0.4235 \\
\hline Heart failure & $7(22 \%)$ & $2(4 \%)$ & 0.013 & $6.58(1.27,34.08)$ & 0.0248 \\
\hline Respiratory failure & $30(94 \%)$ & 37 (76\%) & 0.034 & $4.86(1.01,23.44)$ & 0.0486 \\
\hline NRDS & 29 (91\%) & 34 (69\%) & 0.025 & $4.26(1.12,16.20)$ & 0.0332 \\
\hline $\mathrm{IVH}$ & $16(50 \%)$ & $8(16 \%)$ & 0.001 & & \\
\hline I & 10 & 5 & & $5.13(1.64,15.99)$ & 0.0049 \\
\hline II & 2 & 1 & & $2.56(0.15,43.48)$ & 0.5148 \\
\hline III & 2 & 1 & & $2.56(0.15,43.48)$ & 0.5148 \\
\hline IV & 2 & 1 & & Inf. (0.00, Inf) & 0.9918 \\
\hline Septicemia & $9(28 \%)$ & $10(20 \%)$ & 0.423 & $1.53(0.54,4.31)$ & 0.4246 \\
\hline Premature infant encephalopathy & $20(63 \%)$ & $20(41 \%)$ & 0.056 & $2.42(0.97,6.03)$ & 0.0587 \\
\hline ROP & $21(66 \%)$ & $20(41 \%)$ & 0.029 & $2.77(1.10,6.99)$ & 0.0311 \\
\hline
\end{tabular}

BPD, bronchopulmonary dysplasia; NRDS, neonatal respiratory distress syndrome; IVH, intraventricular hemorrhage; ROP, retinopathy of prematurity; NEC, necrotizing enterocolitis; GRED, gastroesophageal reflux disease; OR, odds ratio; Cl, confidence interval. 
Table 3 Multivariate analysis of clinical data of BPD

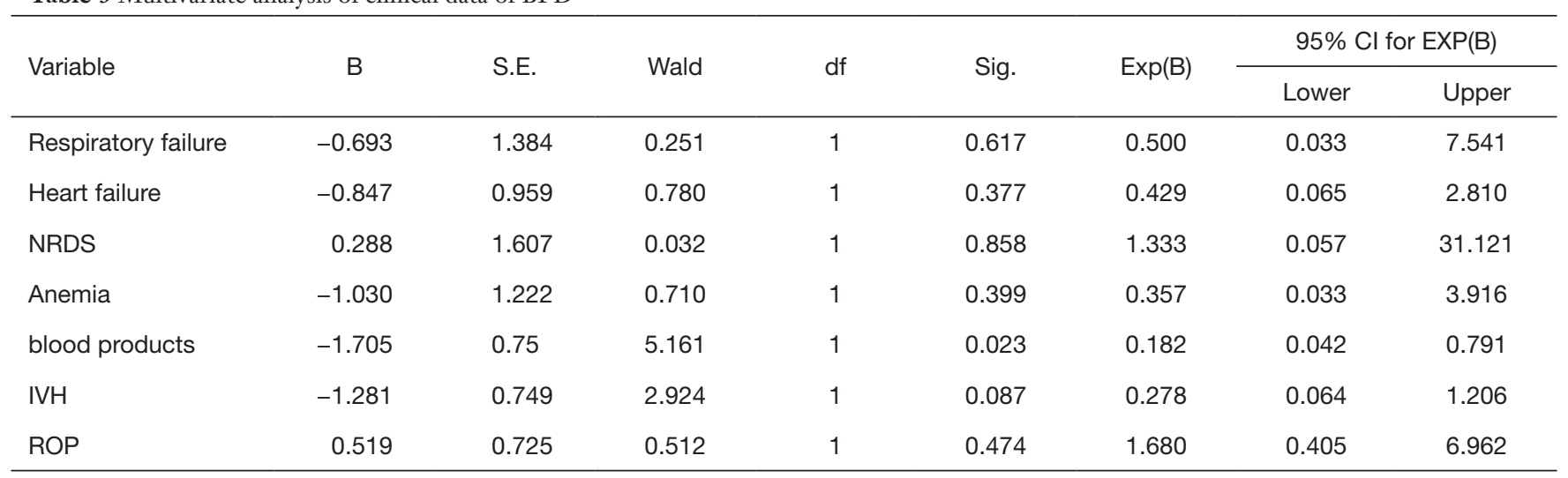

BPD, bronchopulmonary dysplasia; NRDS, neonatal respiratory distress syndrome; IVH, intraventricular hemorrhage; ROP, retinopathy of prematurity.

Table 4 Analysis of lung ultrasound findings in the BPD group and non-BPD group

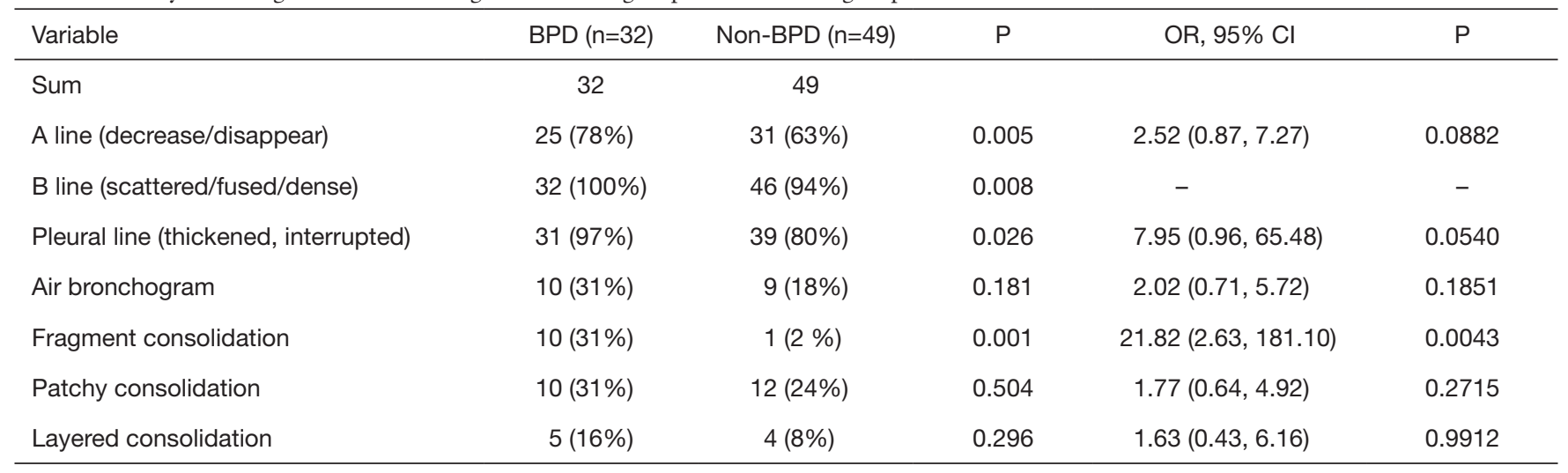

BPD, bronchopulmonary dysplasia; OR, odds ratio; $\mathrm{Cl}$, confidence interval.

risks for adverse neurodevelopmental outcomes that occur during follow-up (12). Studies on BPD from the past 50 years suggest that BPD is mainly caused by mechanical ventilation injury in the near full-term infants at the early stage, while a new kind of BDP often occurs in infants $\leq 28$ weeks' gestational age, with or without mild lung disease at birth, and with no oxygen or low-oxygen treatment being required. However, oxygen dependence gradually develops during hospitalization, with symptoms such as alveolar hypoplasia, disturbance of vascular development, fibrosis of the vesicle wall, and small airway epithelium injury, along with histopathological changes such as reduced alveolar number, increased alveolar volume, simplified alveolar structure, and abnormal microvascular morphology $(7,13)$. Even the cure rate for premature infants is increasing, but the incidence of BPD varies in clinical studies due to the lack of uniform diagnostic criteria (5). According to the study by the NICHD, the incidence of BPD was $39.5 \%$ in the group of 81 infants (gestational age $\leq 28$ weeks, birth weight $\leq 1,500 \mathrm{~g}$ ), which is quite similar to the recent data in China (14).

In our study, the gestational age of BPD was mainly at 28 weeks and with few very premature infants, so it cannot be further analyzed based on different gestational ages. Although we have developed many imaging diagnostic techniques, such as chest radiography, lung computed tomography (CT), lung ultrasound, and lung magnetic resonance imaging (MRI) $(15,16)$, there are few reports discussing the value of different BPD imaging diagnoses (8). Here, we used lung ultrasound technology to test the changes in lung images for infants (gestational age $\leq 28$ weeks, birth weight $\leq 1,500 \mathrm{~g}$ ) and discovered that 
lung ultrasound findings with "debris" sign could be an independent risk factor for BPD disease. Furthermore, due to the advantages of emitting no radiation, being portable, providing convenient bedside monitoring, and being easy to grasp by clinicians, lung ultrasound could be widely used in clinical work (17). A study by Avni et al. showed that infants with ultrasound sonographic images similar to hyaline membrane disease (HMD) had a negative predictive value of $95 \%$ for BPD assessment in the future (18). A similar study indicated that sonographic results on the ninth day after birth also had a prediction of BPD in the long term (19), while other research found that lung ultrasound scores can predict the occurrence of BPD within 1-2 weeks of birth (20). Reviewing 26 clinical prediction models for $\mathrm{BPD}$, Onland et al. found that the risk factors and multiple diagnostic models for predicting BPD proposed in the current study are of low diagnostic value [area under the curve of the receiver operating characteristic curve (AUC of ROC) $=0.5-0.76]$. Moreover, these prediction models had not been applied in clinical work, and little research had confirmed further whether these models' application could improve clinical decision or affect prognosis (21). Most of these investigations focused on the prediction of gestational age, birth weight, gender, Apgar score, mean oxygen concentration, maximum oxygen concentration, peak inspiratory pressure, and oxygenation index, but did not mention image changes in the diagnosis value of BPD. Therefore, our present study focused on ultrasound application in BPD diagnosis and found that the BPDrelated lung ultrasound findings can be further used as a reference for BPD diagnosis, and may also provide a means to identify lung lesions in the early stage.

Limitations of this study may include the small sample size, the small number of special ultrasound signs, and no specific analysis on the occurrence time of characteristic ultrasound images. At present, there is still a controversy over the standardization and quality control of lung ultrasound images, and thus more clinical research to make standardized image acquisition and reading specifications is required.

Ultrasound, an auxiliary diagnostic method for lung diseases, is widely reported to have the advantages of a lack of radiation, simple operation, and easy follow-up. In this study, we deepened the understanding of the characteristic lung ultrasound findings for BPD through analyzing numerous ultrasonic images of very premature infants. We hope this research can facilitate further exploration into the diagnosis and prediction of BPD in the future.

\section{Acknowledgments}

Funding: This work was supported by the Natural Science Foundation of China (81571480).

\section{Footnote}

Conflicts of Interest: All authors have completed the ICMJE uniform disclosure form (available at http://dx.doi. org/10.21037/tp.2020.03.14). The authors have no conflicts of interest to declare.

Ethical Statement: The authors are accountable for all aspects of the work in ensuring that questions related to the accuracy or integrity of any part of the work are appropriately investigated and resolved. The study was approved by Ethics Committee of Chengdu Women's and Children's Central Hospital [No. 2019(37)].

Open Access Statement: This is an Open Access article distributed in accordance with the Creative Commons Attribution-NonCommercial-NoDerivs 4.0 International License (CC BY-NC-ND 4.0), which permits the noncommercial replication and distribution of the article with the strict proviso that no changes or edits are made and the original work is properly cited (including links to both the formal publication through the relevant DOI and the license). See: https://creativecommons.org/licenses/by-nc-nd/4.0/.

\section{References}

1. Jobe AH, Abman SH. Bronchopulmonary Dysplasia: A Continuum of Lung Disease from the Fetus to the Adult. Am J Respir Crit Care Med 2019;200:659-60.

2. Anderson PJ, Doyle LW. Neurodevelopmental outcome of bronchopulmonary dysplasia. Semin Perinatol 2006;30:227-32.

3. Stoll BJ, Hansen NI, Bell EF, et al. Neonatal outcomes of extremely preterm infants from the NICHD Neonatal Research Network. Pediatrics 2010;126:443-56.

4. High Risk Follow-up Working G. Neurodevelopmental outcomes of extreme-low-birth-weight infants born between 2001 and 2002. Hong Kong Med J 2008;14:21-8.

5. Siffel C, Kistler KD, Lewis JFM, et al. Global incidence of bronchopulmonary dysplasia among extremely preterm infants: a systematic literature review. J Matern Fetal Neonatal Med 2019;9:1-11.

6. Northway WH Jr, Rosan RC, Porter DY. Pulmonary 
disease following respirator therapy of hyaline-membrane disease. Bronchopulmonary dysplasia. N Engl J Med 1967;276:357-68.

7. Jobe AH. The new bronchopulmonary dysplasia. Curr Opin Pediatr 2011;23:167-72.

8. Lal CV, Ambalavanan N. Biomarkers, Early Diagnosis, and Clinical Predictors of Bronchopulmonary Dysplasia. Clin Perinatol 2015;42:739-54.

9. Liu J, Xia RM, Ren XL, et al. The new application of point-of-care lung ultrasound in guiding or assisting neonatal severe lung disease treatment based on a case series. J Matern Fetal Neonatal Med 2019:1-9.

10. Ehrenkranz RA, Walsh MC, Vohr BR, et al. Validation of the National Institutes of Health consensus definition of bronchopulmonary dysplasia. Pediatrics 2005;116:1353-60.

11. Xiao TT, Jin M, Ju R, et al. Value of bedside lung ultrasound in the diagnosis of neonatal pneumonia. Zhongguo Dang Dai Er Ke Za Zhi 2018;20:444-8.

12. Steinhorn R, Davis JM, Gopel W, et al. Chronic Pulmonary Insufficiency of Prematurity: Developing Optimal Endpoints for Drug Development. J Pediatr 2017;191:15-21.e1.

13. Carlton EF, Flori HR. Biomarkers in pediatric acute respiratory distress syndrome. Ann Transl Med 2019;7:505.

14. Collaborative Study Group for Bronchopulmonary Dysplasia of Prematurity in C. Incidence and risk

Cite this article as: Gao S, Xiao T, Ju R, Ma R, Zhang X, Dong $W$. The application value of lung ultrasound findings in preterm infants with bronchopulmonary dysplasia. Transl Pediatr 2020;9(2):93-100. doi: 10.21037/tp.2020.03.14 factors of bronchopulmonary dysplasia in premature infants in 10 hospitals in China. Zhonghua Er Ke Za Zhi 2011;49:655-62.

15. Appleby CJ, Towner RA. Magnetic resonance imaging of pulmonary damage in the term and premature rat neonate exposed to hyperoxia. Pediatr Res 2001;50:502-7.

16. Arai H, Ito T, Ito $M$, et al. Impact of chest radiographybased definition of bronchopulmonary dysplasia. Pediatr Int 2019;61:258-63.

17. Touw HR, Tuinman PR, Gelissen HP, et al. Lung ultrasound: routine practice for the next generation of internists. Neth J Med 2015;73:100-7.

18. Avni EF, Cassart M, de Maertelaer V, et al. Sonographic prediction of chronic lung disease in the premature undergoing mechanical ventilation. Pediatr Radiol 1996;26:463-9.

19. Pieper CH, Smith J, Brand EJ. The value of ultrasound examination of the lungs in predicting bronchopulmonary dysplasia. Pediatr Radiol 2004;34:227-31.

20. Alonso-Ojembarrena A, Lubian-Lopez SP. Lung ultrasound score as early predictor of bronchopulmonary dysplasia in very low birth weight infants. Pediatr Pulmonol 2019;54:1404-9.

21. Onland W, Debray TP, Laughon MM, et al. Clinical prediction models for bronchopulmonary dysplasia: a systematic review and external validation study. BMC Pediatr 2013;13:207. 


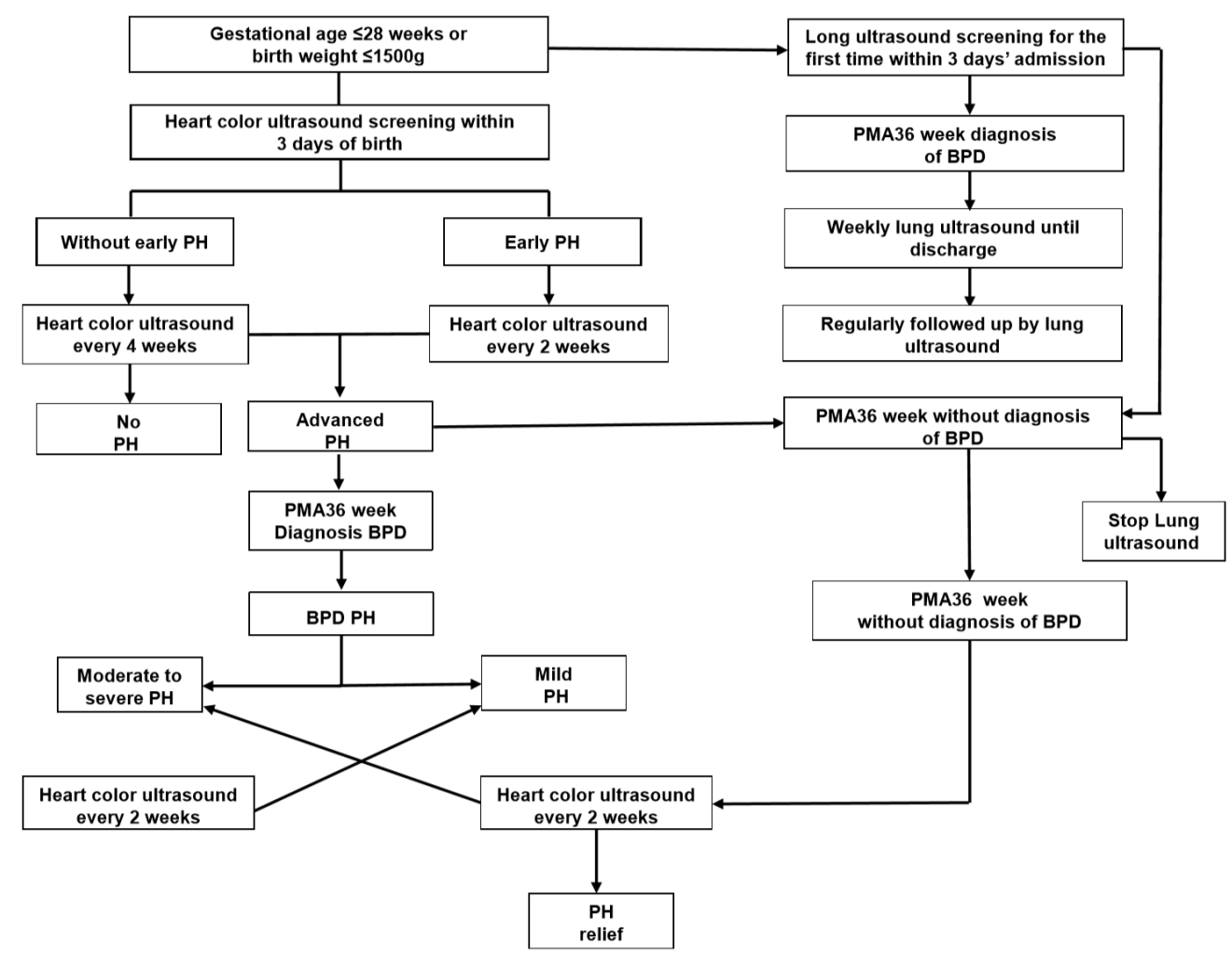

Figure S1 Flow chart of lung ultrasound and heart color ultrasound screening. BPD, bronchopulmonary dysplasia. 